\title{
Enrollment and Retention in Community Health Insurance: Experiences from ICOCARE scheme in South Western Uganda
}

\section{Bosco Turyamureba}

Integrated Community Based Initiative-ICOBI

Freddie Ssengooba

Makerere University School of Public Health

Aloysius Ssennyonjo

Makerere University School of Public Health

\section{Stephen Asiimwe}

Intergrated Community Based Initiatives-ICOBI

\section{Bildard Baguma}

Joint Medical Store-JMS

Angela Kisakye ( $\square$ akisakye@musph.ac.ug )

Makerere University School of Health Sciences https://orcid.org/0000-0001-5472-0474

Christine Kirunga

Makerere University School of Public Health

\section{Research article}

Keywords: Enrollment, retention, Prepayment, ICOCARE scheme, Risk sharing, Community health insurance, premiums, Uganda

Posted Date: August 22nd, 2019

DOl: https://doi.org/10.21203/rs.2.13370/v1

License: (c) (i) This work is licensed under a Creative Commons Attribution 4.0 International License.

Read Full License 


\section{Abstract}

Background: Globally, developing countries have inadequate capacity to raise tax to finance wellfunctioning health systems. In sub Saharan Africa, over $40 \%$ of the total health expenditure comes from households and mostly out of pocket payments. Over $20 \%$ of the population spend more than $10 \%$ of their total household consumption expenditure on health care. Prepayment schemes are crucial for promoting resource pooling and risk sharing to prevent catastrophic health expenditure, yet in Uganda only $1 \%$ of women and less than $2 \%$ of men are covered by health insurance schemes. Private insurance companies cover approximately $12 \%$ of Ugandans who are formally employed. We analyzed factors associated with enrollment and retention in ICOCARE health insurance scheme and examined ways to increase enrollment and reduce dropouts. Methods: This was a cross sectional study which employed both quantitative and qualitative methods of data collection. We interviewed 194 respondents who included both active and non-scheme members of the ICOCARE community health insurance scheme. We conducted three focus group discussions and two key informant interviews with key stakeholders. Quantitative data was analyzed using Statistical Package for Social Scientists software version 20 and STATA 13 while qualitative data was analyzed using the six steps of thematic analysis developed by Braun and Clarke. Results: We found that enrollment and retention into ICOCARE health insurance scheme was influenced by quality of care, extra charges to members, service exclusions, and knowledge of Community Health Insurance principles, previous illness experiences, distance from home to service provider and means of transport used to reach the health facilities. Members living in less than $5 \mathrm{~km}$ to the service provider were 8 times more likely to enroll and retain membership into ICOCARE health insurance scheme [p-value $<0.05$ and $\mathrm{Cl}(3.288-22.302)$ ]. Conclusions: Knowledge on Community Health Insurance principles, benefits and coverage of non communicable diseases which is excluded in most $\mathrm{CHI}$ benefit packages influenced enrollment and retention. Transport costs to service providers deterred potential members from renewal of membership. $\mathrm{CHI}$ schemes need to intensify community education on $\mathrm{CHI}$ principles and identify service providers in areas where members can easily access care to minimize extra costs.

\section{Introduction}

Globally, many developing countries have inadequate capacity to raise tax to finance well-functioning health systems $[1,2]$. Whereas there has been relative political and economic stability in Uganda for close to three decades now, the social and population health indicators have improved but largely remained undesirable [3]. This is partly due to the weak economy which makes access to affordable quality health care inevitably low, given the inextricable relationship of economics and health. Total health expenditure in Uganda is estimated to be US\$56 per capita per annum compared to the WHO recommendation of US\$84 per capita for sub Saharan Africa. In sub Saharan Africa, over $40 \%$ of the total health expenditure comes from households and mostly out of pocket payments. This puts households at the risk of facing high catastrophic payments as well as impoverishment. The low funding of the public health system has been associated with poor health service delivery and low clients' satisfaction in the Uganda Health Sector Financing Strategy 2015/16-2019/20 [4]. 
According to the Health Financing Strategy 2015/16-2019/20, over 20\% of the population spend more than $10 \%$ of their total household consumption expenditure on health care. It is worth noting that out of pocket expenditure has continued to increase with over $50 \%$ of the total out of pocket health expenditure spent on medicines. This scenario is associated with high financial risks and compromises households' consumption of other basic needs. This is one of the key factors which drive most households into extreme poverty in Uganda and other developing countries.

Prepayment schemes are crucial for promoting resource pooling and risk sharing to prevent catastrophic health expenditure, yet in Uganda insurance companies and the Health Management Organizations (HMO's) cover close to 11,000 people who are formally employed and this population is only approximately $12 \%$ of the total population [5].

Community Based Health Financing (CBHF) is one of the ways in which resources for health services can be mobilized. CBHF refers to any scheme that aims at meeting unmet health needs, increasing financial access to health services and is voluntary in nature. Community Health Insurance is also characterized by prepayment of usually a one-time annual fee, risk sharing and community involvement in designing and managing the scheme. The predominant role of the community in CBHIF schemes is mobilizing, pooling, allocating, and managing or supervising health care resources [6].

Through risk sharing, community health insurance protects the poor from unpredictable high costs of health care and also enables them to access timely and quality services. Most of the Community Based Insurance Schemes are based in the Southwestern part of the country. The schemes that have existed for more than 20 years in Southwestern Uganda include Kisizi Hospital scheme and Nyakibale Hospital Scheme.

Previous studies on Community Health Insurance (CHI) in Africa and Uganda in particular indicated that most people enrolled into $\mathrm{CHI}$ schemes in order to have easy access to health care at a subsidized cost and to get access to prompt treatment [7]. Other studies that have been conducted on feasibility and community willingness to enrol in insurance schemes as alternative health financing mechanisms have further shown that informally employed people are willing to join $\mathrm{CHI}$ for improved access to health care services. For example, a study done in Senegal found that community members perceived $\mathrm{CHI}$ as a way of increasing access to quality health care services whenever needed [8].

$\mathrm{CHI}$ has however faced challenges in developing countries which include low enrolment and retention of members, poor quality of care, high premiums, poverty among rural target households and lack of community participation by members in scheme management [7,9]. In Uganda, $\mathrm{CHI}$ still faces low enrolment, despite Government and other partners' interest and support to implement it as one way to mobilize resources for health and improve financial access to health care [10]. Studies in Uganda have identified a number of factors which contribute to low enrolment. They include poverty in households, quality of care by service providers, lack of knowledge about principles of insurance, unfair treatment of scheme members by the health providers and unfair enrolment terms[11]. However, different schemes 
operate under different contexts this therefore calls for research to gain more understanding of factors that influence member enrolment and retention.

In an effort to promote social protection, reduce financial barriers in accessing health care services and guard against catastrophic health expenditure among the rural poor, Integrated Community Based Initiatives-ICOBI, a national Non-Governmental Organization implementing various health related programs initiated a Community Health Insurance scheme named ICOCARE. ICOCARE scheme was started in July 2014 in Sheema District, Southwestern Uganda and was later extend to other districts in the country. It was expected that within a period of one year at least $50 \%$ (i.e., 3,100) households would have joined the ICOCARE scheme in the first 6 target sub-counties. However, by December 2014, only 203 $(6.5 \%)$ out of the expected 3,100 households had enrolled with ICOCARE and 123 (60.5\%) households out of 203 renewed their membership by end of January 2015. This illustrates a low enrolment and relatively high dropout rate in the scheme. However, no studies have been conducted to understand the issues around enrolment and retention in the ICOCARE community health insurance scheme since most studies in Uganda have focused on schemes that were established before 2014. We therefore conducted a study to analyse the factors associated with enrolment and retention and examine ways through which ICOCARE scheme can increase enrolment and reduce dropouts in Sheema District, South Western Uganda.

\section{Methods}

We conducted the study in Kagango and Kigarama sub-counties in Sheema North Health sub district of Sheema District, Southwestern Uganda. The health sub district comprises 6 sub counties, 31 parishes and 339 villages with an estimated population of 130,000 people (Sheema District, 2015). The district has 19 public health facilities including one level IV health center, three level III health centers and 8 level II health centers. There is one private not for profit hospital and 3 private not-for-profit (PNFP) health centers and a number of private for profit clinics.

\section{Study design}

This was a cross-sectional study that employed both quantitative and qualitative methods of data collection. Simple random sampling was used to recruit scheme members and non-scheme members. Purposive sampling was applied to identify respondents for the focus group discussions and key informant interviews.

\section{Study participants}

The study considered three categories of respondents including those enroled and were still active, those who had never joined the scheme and those that enroled but later dropped out of the scheme. We interviewed heads of households/their spouses for two categories of respondents' (i.e., active members and non-scheme members) 
Respondents for FGDs included the scheme dropouts, community mobilisers and scheme staff.

Respondents for key informant interviews were also selected basing on their roles in the ICOCARE scheme management. These were the ICOCARE scheme coordinator and the medical superintendent of Kabwohe Clinical Research Centre (KCRC).

\section{Sample size determination}

We determined the sample size using the formula by (Kish, 1965) at $90 \% \mathrm{Cl}$ and a prevalence of 0.1. A total of 194 respondents were selected for interviews (i.e., 97 scheme members and 97 non-scheme members).

$(\mathrm{ME} / \mathrm{z})^{2}=(\mathrm{p}(1-\mathrm{p})) / \mathrm{n}$

Where; ME is the desired margin of error

$\mathrm{Z}$ is the corresponding $\mathrm{z}$-value

$p$ is the probability of success

$\mathrm{n}$ is the require sample size

At $90 \%$ level of confidence, the $z-v a l u e=1.645$

Our Margin of Error was 0.05 (10\%)

$P=0.1$ and $(1-p)=0.9$

Therefore $(0.05 / 10645)^{2}=(0.1 \times 0.9) / \mathrm{n}$

$0.000924=0.09 n$

$\mathrm{n}=0.09 / 0.000924$

$\mathrm{n}=97$

For the qualitative approach, three focus group discussions were organized with 10-12 members each among scheme dropouts, scheme staff and scheme community mobilisers as well as 2 key informant interviews (i.e., with scheme coordinator and service provider medical superintendent). We conducted interviews on a one on one basis, in the privacy and comfort of the respondent's choice. The numbers of key informant interviews was deemed sufficient when additional interviews yielded little or no new information about the core study objectives.

Data analysis 
The quantitative data were analyzed using Statistical Package for Social Scientists (SPSS) software version 20 and STATA 13. Independent variables were cross tabulated with the outcome variables to determine the signifance of associations. Variables significant in the bivariate analysis ( $p$ value $<$ or $=$ 0.05 ) were entered into multivariate logistic regression to adjust for confounding. Factors in the final model were deemed significant when $p \leq 0.05$. Percentages of respective variables relevant to the study questions were calculated and data are presented using tables and graphs.

Qualitative data were analyzed by first creating codes and categories. Coding frames were discussed and agreed upon by the study team and responses were coded after the field interviews. The coding led to formulation of themes and sub themes from participants' responses in relation to the study objectives. Thematic analysis was used to interprete responses from open ended questions using the six steps of thematic analysis developed by[12]. Direct quotations from the respondents were captured verbatim to give direct understanding and expression of opinions from the study respondents.

\section{Results}

\section{Socio Demographic Characteristics of Respondents}

We interviewed 97 active scheme members and 97 non active scheme members. The average age among respondents was 46 years ( \pm SD 1.175). We also found that almost half $(54 \%)$ of the respodents were females and only 64 (32\%) of the respondents had no education. Twenty six percent of the respondents were engaged in trade as an occupation while $70 \%$ came from less than $5 \mathrm{~km}$ distance to the service provider.

\section{Factors associated with enrolment and retention}

At bivariate analysis, we found that respondents with primary level of education and above were 8 times more likely to enrol and be retained in the scheme $\square^{2}$ (p-value) 8.069 (0.045). The findings also indicated that respondents residing in less that $5 \mathrm{~km}$ distance from the health facilities that provided health insurance service were 9.4 times more likely to enrol and retain membership in the ICOCARE scheme $\square^{2}(p-$ value) 9.358 (0.002) (Table 1).

Table 1: Bivariate model of factors associated with enrolment and retention in ICOCARE Health Insurance scheme, South Western Uganda, 2016-2017 


\begin{tabular}{|c|c|c|c|c|}
\hline Characteristic & $\begin{array}{l}\text { Scheme } \\
\text { Members } \\
\text { n=97 (\%) }\end{array}$ & $\begin{array}{c}\text { Non-Scheme } \\
\text { members } \\
n=97(\%)\end{array}$ & $\begin{array}{c}\text { Total } \\
\mathrm{n}=194 \\
(\%)\end{array}$ & $\begin{array}{l}\square^{2}(p- \\
\text { Value })\end{array}$ \\
\hline $\begin{array}{l}\text { Age, years. (Median, IQR) } \\
20-30 \\
31-40 \\
41-50 \\
51-60 \\
61-70 \\
\text { SD }\end{array}$ & $\begin{array}{l}46(29-58) \\
08(8.3) \\
10(10.3) \\
37(38.1) \\
25(25.8) \\
17(17.5) \\
1.126\end{array}$ & $\begin{array}{l}45(27-63) \\
07(7.2) \\
12(12.4) \\
19(19.6) \\
34(35.1) \\
25(25.8) \\
1.212\end{array}$ & $\begin{array}{c}46(27- \\
65) \\
\\
1.175\end{array}$ & $\begin{array}{c}0.205 \\
(0.903)\end{array}$ \\
\hline $\begin{array}{l}\text { Sex } \\
\text { - Females } \\
\text { - Males }\end{array}$ & $\begin{array}{l}50(52) \\
47(48)\end{array}$ & $\begin{array}{l}55(57) \\
42(43)\end{array}$ & $\begin{array}{c}105 \\
(54) \\
89(46)\end{array}$ & $\begin{array}{c}0.519 \\
(0.471)\end{array}$ \\
\hline $\begin{array}{l}\text { Education } \\
\text {-None } \\
\text {-Primary } \\
\text {-Secondary } \\
\text {-Tertiary }\end{array}$ & $\begin{array}{l}32(33) \\
22(23) \\
16(16) \\
27(28)\end{array}$ & $\begin{array}{l}32(33) \\
37(38) \\
14(14) \\
14(14)\end{array}$ & $\begin{array}{l}64(32) \\
59(30) \\
30(16) \\
41(21)\end{array}$ & $\begin{array}{c}8.069 \\
(0.045)\end{array}$ \\
\hline $\begin{aligned} & \text { Occupation } \\
& \text { - } \text { Farmers } \\
&- \text { Traders } \\
&- \text { Students } \\
&- \text { Formal } \\
& \text { Employment } \\
&- \text { Unemployed } \\
&- \text { Others }\end{aligned}$ & $\begin{aligned} 20 & (21) \\
27 & (28) \\
9 & (9) \\
13 & (13) \\
8 & (8) \\
20 & (21)\end{aligned}$ & $\begin{aligned} 19 & (20) \\
24 & (25) \\
7 & (7) \\
15 & (15) \\
8 & (8) \\
23 & (24)\end{aligned}$ & $\begin{array}{c}39(20) \\
51(26) \\
16(8) \\
28(14) \\
16(8) \\
43(22)\end{array}$ & $\begin{array}{c}0.799 \\
(0.977)\end{array}$ \\
\hline $\begin{array}{l}\text { Distance from Home to } \\
\text { Facility }(\mathrm{n}=173) \\
\begin{aligned}-\quad<5 \mathrm{~km} \\
-\quad>5 \mathrm{~km}\end{aligned}\end{array}$ & $\begin{array}{l}44(58) \\
32(42)\end{array}$ & $\begin{array}{l}77(79) \\
20(21)\end{array}$ & $\begin{array}{c}121 \\
(70) \\
52(30)\end{array}$ & $\begin{array}{c}9.358 \\
(0.002)\end{array}$ \\
\hline
\end{tabular}

\section{Multivariate analysis}

At multivariable analysis, all independent factors with $p<0.05$ were run into a multivariable generalized linear model to obtain the adjusted prevalence ratios. We also included variables that are known to affect enrolment and retention in related $\mathrm{CHI}$ schemes in our analysis. Forward stepwise method was used to select variables to include in the final model. Variables that were included in the final model were; age, sex, education, ability to pay premiums, reported poor quality of services, transport means and distance from the scheme member to service providers. The results of this analysis indicate that having secondary or higher education and shorter distance less than $5 \mathrm{~km}$ OR $2.088 .56 \mathrm{Cl}(0.91-4.79)$; having the ability to pay OR $0.9 \mathrm{Cl}(0.63-1.29)$ were significantly associated with enrolment and retention into ICOCARE scheme (Table 2). 
Table 2: Multivariate model of factors associated with enrollment and retention in ICOCARE Health Insurance scheme, South Western Uganda, 2016-2017

\begin{tabular}{lcc}
\hline Characteristic & OR & 95\% CI \\
\hline Age & 1.24 & $0.68-2.27$ \\
\hline Sex (Female vs Males) & 1.09 & $0.56-2.13$ \\
\hline Education (none=ref) & 1.03 & $0.56-1.86$ \\
$-\quad$ Primary vs None & 2.08 & $0.91-4.79$ \\
$-\quad$ Secondary vs None & 3.88 & $1.75-8.62$ \\
\hline$\quad$ Tertiary vs None & 8.56 & $3.29-22.30$ \\
\hline Distance to Facility (<5Km vs >5km) & 0.56 & $0.15-2.03$ \\
\hline Transport Means (Walking = ref) & 0.96 & $0.45-2.07$ \\
$\quad$ - Cyclist (boda) vs Walking & 0.90 & $0.63-1.29$ \\
\hline Ability to Afford Premium (Yes vs No) & 0.92 & $0.62-1.37$ \\
\hline Reported poor Quality of Services (Yes Vs No) & & \\
\hline
\end{tabular}

\section{Client related factors that influence enrolment and retention}

We further analyzed key factors from the scheme and non-scheme members' perspective in the quantitative analysis. Key quality dimensions of access, cost and quality were used to identify factors including means of transport, ability to pay premium and also reported quality of care of scheme services.

Table 3: ICOCARE Scheme and non-scheme members' perspective on the quality, access and cost of care 


\section{Characteristic}

$\begin{array}{cccc}\text { Scheme } & \text { Non-Scheme } & \text { Total } & \square^{2}(p- \\ \text { Members } & \text { members } & n= & \text { Value) } \\ \mathrm{n}=97(\%) & \mathrm{n}=97(\%) & 194 & \end{array}$

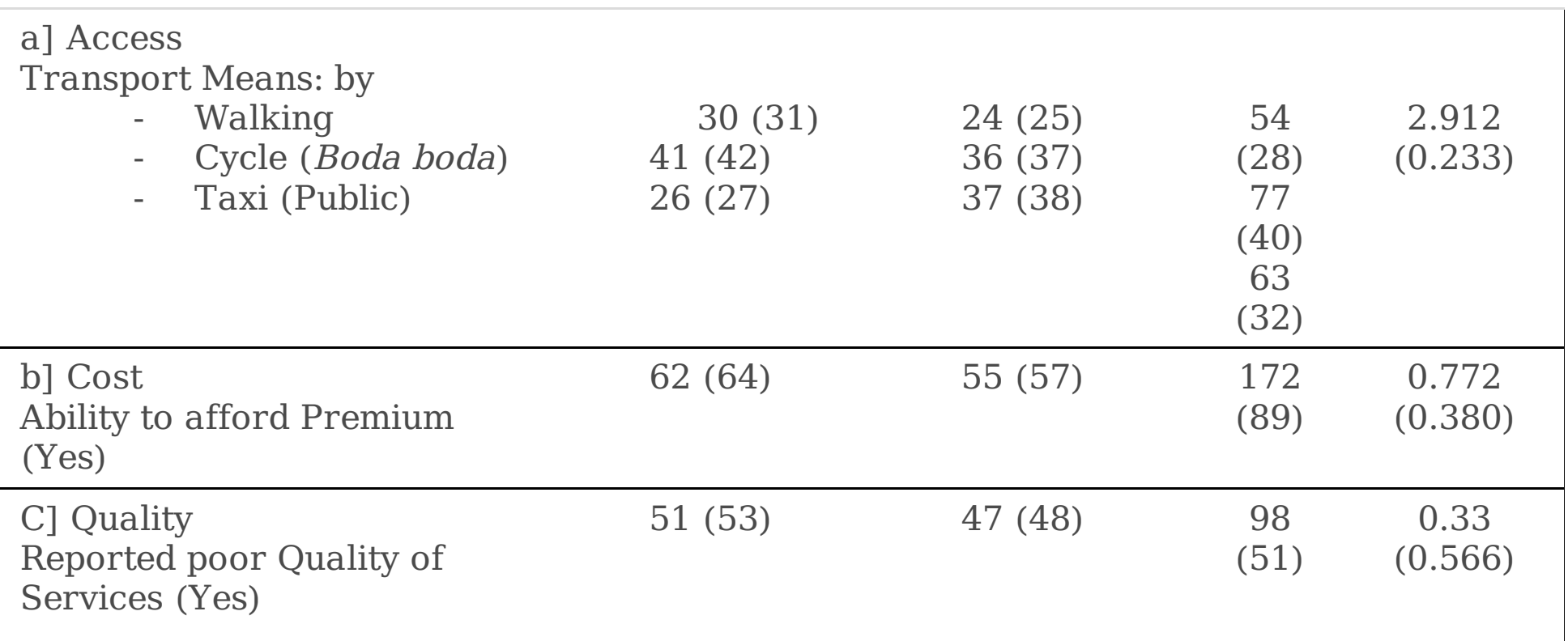

We found out that less than half $40 \%$ of the respondents used boda bodas to reach the service provider. Eighty nine percent of the respondents indicated ability to pay the premium of the scheme which was 22 USD per a family of 4 members annually.

We also analyzed the qualitative aspects of the findings to add more meaning to the quantitative findings. These were generated from the themes developed during analysis and categorized under health provider related factors, scheme related factors and contextual factors.

>Health service provider related factors

We analysed factors from the health service provider perspective to understand what influences enrolment and retention of members in ICOCARE scheme. The main factors that arose from the analysis included waiting time at facility, health workers willingness to assist clients and availability of drugs prescribed to scheme members.

Waiting time at facility

Majority of the active scheme members reported that they waited for an hour before they could see a health worker. Some drop out members in a focus group discussion identified long waiting time at the facility as a major challenge which leads to delayed services. This can be illustrated by the following quote.

"The health workers mind more about those paying cash for services, for us we are made to wait for long hours without seeing a doctor, health workers are even rude. "Female respondent in, Kigarama Sub County. 
A focus group discussion with community mobilisers revealed that scheme members tend to think they should be rendered special care irrespective of other sickly patients. One of the medical superintendents of a health facility stressed the fact that facilities provide care on a first come first served basis and priorities very sick/emergency patients.

Assistance by health workers to clients

Active scheme members were asked about assistance provided by the health workers while at the facility to ease access to care. Majority of the respondents appreciated the assistance provided when they visited the providers while some felt that they were not assisted to access care at the faciliies. Focus group discussions with scheme drop out respondents also revealed that they were not well handled at the facility. Rudeness of some health workers was mentioned as one of the key issues as illustrated below.

"Nurses respond to you rudely when you ask for help at the facility, they do not want to help or respond incase you call them to check on a sick person." (Male respondent, Kagango Sub-County)

\section{Lack of prescribed drugs at service provider facility}

During focus group discussion with scheme drop outs, it was noted that some respondents did not renew membership due to lack of essential prescribed drugs by the provider. Respondents expected the scheme to provide all prescribed medicines to members since they had paid their premiums for the period.

"Why should i buy drugs outside the facility after subscribing membership and why do health workers prescribe drugs they do not have at the facility?" (Male drop out respondent in Kigarama sub county)

Scheme related factors

We analysed factors related to design and management of ICOCARE scheme with focus on the following themes; enrolment terms, community mobilisation, extra charges and exclusions.

\section{Enrolment terms}

We found out that some of the scheme members appreciated the minimum of 4 members enrolment since sickness is not predetermined. However, during an FGD with scheme drop outs, they revealed discomfort with the requirement of minumum 4 members per household. The arguement was that some of the people were living individually in homes or with fewer members and preferred to pay for only their exact members. This was noted to be a barrier to enrolment for some households and also a reason for drop outs in ICOCARE scheme.

"Why should i pay for 4 members/people yet we are just two in a home, this is unfair to some of us." (Female drop out repondent in Kigarama sub county).

Community mobilization 
A focus group discussion with drop outs revealed that some members would wish to renew their membership but could not easily get community mobilisers for the scheme to pay their premiums and hence ended up dropping out.

"We used to have ICOCARE mobilisers visiting our homes to educate us about the scheme and also collect our premiums but we nolonger see them, that is why some of us failed to renew and ended up dropping out." (Male scheme drop respondent in Kagango sub county).

\section{Extra charges}

The provider charges for services outside the scheme benefit package to members. These extra charges especially diagnositc procedures in addition to co-payment on scheme members came up strongly as a key reason for discontent. Sixty seven percent of the respondents that were enroled into the scheme indicated that extra charges pose a burden to them especially for key services like X-ray, diabetic drugs and other laboratory tests not fully covered by the scheme. Drop out respondents indicated these costs as one reason for not renewing membership as the scheme became expensive.

"The scheme premium appears affordable but when you visit the facility you pay more money on several investigations" (Male drop out respondent in Kigarama sub county).

\section{Service exclusions}

Respondents revealed that the key services that had motivated them to join the scheme were not being provided under ICOCARE scheme. Respondents noted that at initial enrolment the mobilisers did not clearly indicate what was involved in exclusions but only focused on the benefits to attract them into the scheme. Among the key services of concern were diabetic services, contributions for X-ray and ultra sound where a members are asked to contirbute $50 \%$ of the total cost. Scheme exclusions were a key issue during focus group discussions among the drop outs from the ICOCARE scheme.

"I joined because of the benefits in the scheme which are now excluded and charged highly, I found no reason to keep my membership." (Female drop out, Kagango sub county).

The respondents mentioned that the scheme package does not address critical health needs especially for the family heads who contribute premiums for other family members.

\section{Contextual factors}

We found that political climate partly influenced enrolment and retention in the scheme. The period between July 2014 to end of 2015 was an election period for parliamentary and presidential elections in Uganda. The community members were seeking for key services from political aspirants and the candidates were also promising quality free health care services once voted into offices. The Government opponents in the region and Sheema District in particular interpreted Community Health Insurance Scheme as a failure by Government to provide citizens with basic health services. A FGD with scheme 
drop outs observed that some members were discouraged by political aspirants who advocated for Governments sole responsibility in health care service provision.

"The parliamentary candidates told us to demand free quality health services from Government and discouraged us from joining prepayment schemes like ICOCARE" (A male drop out respondent, Kagango sub county).

\section{Discussion}

We found out that the level of education, distance from scheme service provider and ability to pay premiums were factors associated with enrolment and retention into ICOCARE scheme. We also found out that quality of care, enrolment terms and exclusion criteria of the benefit package and political interferance influenced enrolment and retention in ICOCARE scheme.

Level of education was significantly associated with enrolment and retention into the ICOCARE scheme. People who had a higher level of education were more likely to enrol and stay in the scheme. This finding supports similar findings from a meta analysis by (David, 2016) which found a positive association between education of the head of household and enrolment in 81 of the respondents. Other studies about enrolment and retention that were conducted in Senegal and Bushenyi district, in Uganda reported a positive association between household head's educational level and enrolment in CBHI $[13,14]$. This could be due to the fact that people with a higher level of education easily appreciate the principles of $\mathrm{CHI}$ compared to those with lower education levels. Also the risk perceptions among the educated is higher which motivates people to enrol and stay on HI schemes. In addition, most of the educated people tend to have better incomes compared to the uneducated which makes it simpler for them to pay premiums and renew scheme membership.

Distance and associated transport costs to the service provider were identified as key limitations to enrolment and retention in the ICOCARE scheme. ICOCARE Scheme members spent an average of 4 USD per visit compared to non members who spent an average of 2USD shillings to access care. We noted that variations between members and non scheme members were partly because non members visit nearby clinics not necessarily the scheme accredited facilitities which are distant.

Ability to pay premiums was another factor associated with enrolment and retention into ICOCARE scheme. Respondents revealed that lack of basic needs like food made it difficult to join the health insurance scheme since it was not an immediate need. This finding relates to a survey that was done in Rwanda $\mathrm{CHI}$ schemes which revealed that poverty was the main reason for the not enroling into the scshemes [15]. Another study revealed that wealthier members were more likely to enrol into community health insurance schemes. Related sudies show that it is paramount to look into issues of premiums to be sure that the targeted communities are willing and able to pay the set premiums $[9,13,16]$. However in contrast to our study, Schneider [15] found out that poor hoseholds are more likely to enrol into CHI so as to avoid credit constraints in averting health risks. However, Schneider [15] noted that people were less likely to pay premiums for health care services that would be utilised at a later time in future, if they were 
struggling to secure daily household basic needs. A study by Mohammad Iqbal [16] in Chakaria Bangladesh found that even amidst poor socio economic conditions, the poor can renew membership if they appreciate the quality of care provided. The inability to enrol and stay on the ICOCARE scheme by the poorer people in Sheema District could be because the poor tend to have limited resources that cannot even meet immediate household needs like food, shelter and clothings. This makes it hard for the poor to make choices especially joining a community health insurance scheme that does not provide immediate needs. Also the poor are likely to have low risk perception to illness or even resort to herbal medicine incase they fall sick.

We found out that quality of health care services influenced enrolment and retention of members in ICOCARE scheme. Quality elements expressed by respondents included ability to see a clinician timely, availability of prescribed drugs, access to key diagnosis services and assistance from health workers to access care. Respondents prefered to spend a shorter time at the facility and access care timely and be provided with the prescribed drugs. Similar studies reveal that some of the aspects of health care quality that community members would need to be addressed to join and remain in $\mathrm{CHI}$ schemes include good attitude of health workers, availability of medicines, reduction of waiting time, distance to the health facilities and the operational time of health service providers $[7,14]$.

However, in another study conducted by Basaza [13], there was no evidence on how quality affected enrolment into the $\mathrm{CHI}$ schemes. Other related studies indicate that quality of health care under community health insurance schemes remains a key determinant of members' enrolment and retention $[8,9,17,18]$. We found out that unfair treatment of scheme members compared to non members by the health providers affects enrolment and retention. We found that rudeness of some health workers was a barrier to renewal of membership and this affected retention negatively. This could be due to the fact that non scheme members pay out of pocket to access health care compared to scheme members that pay premiums in advance. Also scheme members are likely to demand for more attention from health workers than non members and this is likely to negatively affect the attitude of health workers and as a result affect members perception of quality of care at health facilities.

We found out that enroling a minimum of 4 members per household with each paying a premium of 5.5USD per year was a barrier to enrolment for households that had less than four members. The respondents perceived this principle as unfair. A similar study on $\mathrm{CHI}$ schemes in South Western Uganda also revealed that schemes had limited enrolment partly because of inappropriate entrance rules [13]. This enrolment principle aimed at reducing adverse selection among enroled members so that the scheme becomes viable to implement. However, people in the community find it hard to appreciate and feel cheated if they pay for more members than those actually in the household.

Service exclusions especially for chronic illnesses such as diabetes and hypertension affected enrolment and retention of members. ICOCARE scheme members complained about the exclusions for chronic illnesses, which affect the majority of household heads that not only make decisions on household scheme membership but also incur scheme premiums. This relates to a study conducted by Musau [19] 
on Kisizi Hospital scheme which found out that an appropriate benefit package that meets the needs of members is critical in promoting enrolment and retention. Due to the benefit exclusions, scheme members were required to pay for services not covered under the ICOCARE scheme service package. Service exclusions therefore influenced enrolment and retention of members in ICOCARE scheme in Sheema District. This could partly be due to lack of adequate knowledge about health insurance principles and also low premiums that might not cover chronic illnesses among the community members.

The political climate influenced enrolment and retention of members in the ICOCARE scheme. We noted that some people did not enroll into the scheme due to political debates that were going on concerning the Government role on health care service provision. A number of respondents were discouraged by political aspirants for parliamentary seats who were advocating for free health services instead of people paying from their little incomes. This was one key factor noted due to the timing of ICOCARE scheme enrolment that collided with the campaign period in Uganda. Though this issue in not cited in most related studies, it portrays the need for a clear policy by the Ministry of Health in Uganda on $\mathrm{CHI}$ in the context of free health care.

The study findings provide useful insights into understanding $\mathrm{CHI}$ schemes in Uganda especially the underlying issues that justify why enrolment has remained low. $\mathrm{CHI}$ scheme managers need to look into issues of access to health care by members, community education on $\mathrm{CHI}$ principles, designing appropriate benefit packages that address health needs of target communities among others.

One of the limitations of this study was the small sample, which could not be used to generalize the factors that affect enrolment and retention across various schemes. Also, a few variables were analyzed in respect to scheme retention due to limited time of the study and resource envelope. However, the findings of this study provide useful insights in regard to effective design and management of a successful $\mathrm{CHI}$ scheme.

\section{Conclusions}

Our study findings indicate that short distance to service providers, ability to pay premiums, quality of health care, enrolment terms and high levels of education positively influence enrolment and retention in the ICOCARE scheme. Similar CHI schemes should ensure provision of quality care and availability of drugs prescribed to members. Also mistreatment by health workers, extra costs, service exclusion as well as knowledge gap about the principle of resource pooling were key factors that negatively affected enrolment and retention in ICOCARE scheme.

\section{Recommendations}

Increasing access to health facilities that offer community health insurance services, availing prescribed drugs to members, reviewing enrolment terms and intensive community mobilisation can improve enrolment and retention of members in $\mathrm{CHI}$ schemes. $\mathrm{CH}$ schemes need to design benefit packages that address health needs of the target communities and enroled members and should clearly indicate 
services that will be offered from the onset of the scheme. Governments through Ministry of health should provide a guiding policy framework to minimise political interferences into the $\mathrm{CHI}$ relevance.

In addition, community education and sensitisation on $\mathrm{CHI}$ principles and general health needs at community level are important in improving people's understanding and uptake of $\mathrm{CHI}$ schemes leading to increased enrolment and retention.

\section{Declarations}

Ethics approval and consent to participate

We received ethical approval to conduct the study from Makerere University Higher Degrees Research and Ethics Committee. In addition, we obtained informed verbal consent from each participant before the interview. Participation in this study was voluntary and each participant was free to participate or not.

\section{Consent for publication}

The authors fully accept and consent to publication of this material.

\section{Availability of data and materials}

Data to this study is available on request from the corresponding author.

\section{Competing interests}

We declare that we have no competing interests

\section{Funding}

This study was undertaken as part of a Fellowship programme in Health Systems Management. The Fellowship programme was jointly supported by Makerere School of Public Health, the Uganda Ministry of Health, the Institute of Tropical Medicine in Antwerp and the Belgian Development Cooperation. The research component was supported with funding from SPEED Project at Makarere School of Public Health with support from European Union.

\section{Author's contributions}

Authors' contributions BT and AS designed the study. ANK and FS provided scientific support and guidance to $B T$ during the manuscript preparation. $K R, K A$ and $B B$ provided general supervision for the research process, contributed to the data analytic process and reviewed and commented on early drafts of the manuscript. KA, AS and KR provided feedback on emerging findings from the study and reviewed and provided comments on manuscript drafts. All authors critically reviewed and approved the current version of the manuscript. 
We thank the individuals who contributed to this study by participating in individual interviews and focus group discussions. Robert Baijuka and Atuhaire Harriet collected the data. Tweteise Anthony coordinated data collection activities and provided continuous supervision of interview procedures and feedback on data quality.

\section{References}

1. Balabanova D, Mills A, Conteh L, Akkazieva B, Banteyerga H, Dash U, et al. Good Health at Low Cost 25 years on: lessons for the future of health systems strengthening. The Lancet. 2013;381(9883):2118-2133.

2. Chemouni B. The political path to universal health coverage: Power, ideas and community-based health insurance in Rwanda. World Development. 2018;106:87-98.

3. Kotoh AM, Van der Geest S. Why are the poor less covered in Ghana's national health insurance? A critical analysis of policy and practice. International journal for equity in health. 2016;15(1):34.

4. Government of Uganda. Health Sector Development Plan 2015/16-2019/20. Ministry of Health; 2015.

5. Fenny AP, Asante FA, Enemark U, Hansen KS. Treatment-seeking behaviour and social health insurance in africa: the case of Ghana under the National Health Insurance Scheme. Global journal of health science. 2015;7(1):296.

6. World Health Organization. Community based health insurance schemes in developing countries: facts, problems and perspectives/by Guy Carrin. In: Community based health insurance schemes in developing countries: facts, problems and perspectives/by Guy Carrin. 2003.

7. Basaza R, Criel B, Van der Stuyft P. Low enrolment in Ugandan Community Health Insurance Schemes: underlying causes and policy implications. BMC health services research. 2007;7(1):105.

8. Ouimet MJ, Fournier P, Diop I, Haddad S. 2006 PPH STUDENT AWARD PROGRAM-Solidarity or Financial Sustainability: An Analysis of the Values of Community-based Health Insurance Subscribers and Promoters in Senegal. Canadian Journal of Public Health. 2007;98(4):341-346.

9. Criel B, Waelkens MP. Declining subscriptions to the Maliando mutual health organisation in GuineaConakry (West Africa): what is going wrong? Social science \& medicine. 2003;57(7):1205-1219.

10. Basaza R, Criel B, Van der Stuyft P. Community health insurance in Uganda: why does enrolment remain low? A view from beneath. Health Policy. 2008;87(2):172-184.

11. Dakoye D, Anguyo RO, Govule P, Katongole SP, Ayiko R, Nabyonga-Orem J. Communities' willingness to pay for healthcare in public health facilities of Nakasongola district, Uganda. 2015;

12. Braun V, Clarke V. Using thematic analysis in psychology. Qualitative research in psychology. 2006;3(2):77-101.

13. Basaza R. Community health insurance in Uganda: status, obstacles and prospects. Ghent University; 2011. 
14. Dror DM, Hossain SS, Majumdar A, Koehlmoos TLP, John D, Panda PK. What factors affect voluntary uptake of community-based health insurance schemes in low-and middle-income countries? A systematic review and meta-analysis. PLoS One. 2016;11(8):e0160479.

15. Schneider P. Why should the poor insure? Theories of decision-making in the context of health insurance. Health policy and planning. 2004;19(6):349-355.

16. Iqbal M, Chowdhury AH, Mahmood SS, Mia MN, Hanifi SMA, Bhuiya A. Socioeconomic and programmatic determinants of renewal of membership in a voluntary micro health insurance scheme: evidence from Chakaria, Bangladesh. Global health action. 2017;10(1):1287398.

17. Kyomugisha EL, Buregyeya E, Ekirapa E, Mugisha JF, Bazeyo W. Strategies for sustainability and equity of prepayment health schemes in Uganda. African health sciences. 2009;9(2).

18. Fadlallah R, El-Jardali F, Hemadi N, Morsi RZ, Samra CAA, Ahmad A, et al. Barriers and facilitators to implementation, uptake and sustainability of community-based health insurance schemes in low-and middle-income countries: a systematic review. International journal for equity in health. 2018;17(1):13.

19. Musau SN. Community-based health insurance: experiences and lessons learned from East and Southern Africa. Partnerships for Health Reform, Abt Associates; 1999. 